\title{
ASSESSMENT OF MICROSATELLITE MARKERS (SSRs) FOR GENETIC DIVERSITY IN ASPARAGUS OFFICINALIS L. AND ALLIED SPECIES
}

\author{
Muhammad Idrees ${ }^{1}$, Muhammad Irshad, Mitra Lal PathaK ${ }^{2}$, \\ AKash TariQ ${ }^{3}$ and Rehan NaEeM* \\ Department of Biotechnology and Genetic Engineering, Kohat University of Science and \\ Technology (KUST), Kohat. 26000, Pakistan
}

Keywords: Asparagus, Simple sequence repeats, Polymorphism, Cluster analysis, UPGMA

\begin{abstract}
The present study was hypothesized to evaluate a set of SSRs for the assessment of genetic variations in Asparagus officinalis L. and their allied species. Nine genic SSR markers were especially developed for Asparagus genome and employed for DNA profiling studies of Asparagus species. These SSRs markers have revealed the allelic polymorphism ranging from 1.0 to 2.0. Allele frequency was found highest for psbD-trnL (1.0), petB (1.0) and AG7 (1.0), while it was lowest for ZHD1 (0.1). Polymorphism Information content (PIC) was highest for TC7 (0.9) while it was lowest $(0.0)$ for psbD-trnL, petB and AG7 respectively. The genetic similarity coefficients were found to range from 0.42 to 1.0. The UPGMA clustering algorithm based on SSRs data have clustered Asparagus species into 4 groups (I, II, III \& IV) indicating Asparagus officinalis (L.) cultivars and allied species in the first clade, while Asparagus officinalis (L.) 'Gersengum', Asparagus densiflorus (Kunth) Jessop, and Asparagus racemosus willd. were clustered in separate clades respectively. The present study has endorsed the origin status of Asparagus officinalis and their allied species. A. officinalis cultivars and other allied Asparagus species are clustered in separate clades, and it was revealed that they have monophyletic origin. It was established that SSRs markers could be informative markers for the differentiation of Asparagus officinalis cultivars, and their allied Asparagus species.
\end{abstract}

\section{Introduction}

Asparagus L. (Asparagaceae) contains more than 210 species, dispersed throughout the world from temperate to tropical regions (Kanno and Yokoyama 2011). Asparagus is grown particularly for their nutritional, ornamental and medicinal purposes. Asparagus officinalis L. (Garden Asparagus) is an important vegetable crop grown in a wide diversity of environments, while other species have long been used for medicinal purposes and are included in traditional pharmacopoeia (Asparagus racemosus willd., A. verticillatus L., A. adscendens Roxb.), and many others are considered as ornamental (A. plumosus Baker, A. densiflorus (Kunth) Jossop, A. virgatus Baker) (Kumar et al. 2015). Recent phylogenetic studies on the genus Asparagus (Kubota et al. 2012, Norup et al. 2015) have confirmed their monophyletic origin with sexual dimorphism and polyploidy as the main force of evolution (Castro et al. 2013). Asparagus officinalis L. has been used as a vegetable globally for a long time, making it as an economically valuable plant. It has also been reported that continuous use of Asparagus officinalis can stimulate insulin levels in the blood, which is helpful for improving type 2 diabetes and protecting liver cells (Hafizur et al. 2012). Furthermore, they also possess anti-inflammatory, antimicrobial, and anti-cancerous

*Author for correspondence: <dr.rehan@kust.edu.pk>. ${ }^{1}$ College of Life Science, Neijiang Normal University, Neijiang 641000, Sichuan, China. ${ }^{2}$ Chengdu Institute of Biology, Chinese Academy of Science, P.O Box 416, Chengdu 61004, China. ${ }^{3}$ Xinjiang Institute of Ecology and Geography, Chinese Academy of Sciences, Urumqi, China. 
components (Fuentes-Alventosa et al. 2009). These are distributed in two forms including white Asparagus, in which the spears are white, and their young stems are harvested from raised beds, and green Asparagus, in which the spears are green, and harvested at ground level. These Asparagus becomes green when it receives light, while it becomes white when their exposure to light is blocked. This variation is associated with differences in rutin and protodioscin contents of Asparagus (Maeda et al. 2005). Green Asparagus has a higher content of rutin, while white Asparagus has a higher content of protodioscin (Lee et al. 2010). Recently, there is great attention on the breeding programs of Asparagus species to increase the concentrations of valuable phytochemicals. However, the feasibility of genetic improvement must need to be first established, including an investigation into the presence of heritable variability in available populations. Genetic diversity plays a vital role in identifying the scenario for genetic improvement of genotypes, germplasm management and selection of the elite genotypes (Engles et al. 2002). Various types of data sets have been used for such purposes, for which DNA markers are more reliable (Ray et al. 2010).

DNA based molecular markers are independent of environmental influences (Kalpana et al. 2004). Recently, microsatellites or simple sequence repeats (SSRs) are widely used for assessing genetic variations, gene flow characterization and linkage disequilibrium (Koppolu et al. 2010). Limited studies are available for the assessment of genetic polymorphism, origin, and evolution of Asparagus species available in Pakistan. Thus, the present study was hypothesized to evaluate a set of SSRs markers for the assessment of genetic variations of Asparagus officinalis and their allied Asparagus species

\section{Materials and Methods}

Six Asparagus officinalis (L.) cultivars and eight Asparagus allied species, which were cultivated in Asparagus cultivation and breeding programs of Pakistan, were collected from Agriculture Research Institute, Mingora and other temperate or tropical regions of Pakistan (Table S1).

Table S1. List of Asparagus species, locality, and their use

\begin{tabular}{|c|c|c|c|}
\hline No. & Names & Locality & Use \\
\hline 1 & Asparagus officinalis (L.) & Punjab, Islamabad & Vegetative \\
\hline 2 & Asparagus officinalis (L.) 'Apollo' & $\mathrm{KPK}^{*}$, Swat & " \\
\hline 3 & Asparagus officinalis (L.) 'Abril' & $\mathrm{KPK}^{*}$, Swat & $"$ \\
\hline 4 & Asparagus officinalis (L.) 'Huchel' & $\mathrm{KPK}^{*}$, Swat & $"$ \\
\hline 5 & Asparagus officinalis (L.) 'Gersengum' & $\mathrm{KPK}^{*}$, Swat & $"$ \\
\hline 6 & Asparagus officinalis (L.) 'Para' & $\mathrm{KPK}^{*}$, Swat & " \\
\hline 7 & Asparagus officinalis (L.) 'Taranga' & $\mathrm{KPK}^{*}$, Swat & $"$ \\
\hline 8 & Asparagus adscendens Roxb. & $\mathrm{KPK}^{*}$, Kohat & Medicinal \\
\hline 9 & Asparagus capitatus Baker & $\mathrm{KPK}^{*}$,Swat & $"$ \\
\hline 10 & Asparagus gracilis Salisb & $\mathrm{KPK}^{*}$, Swat & $"$ \\
\hline 11 & Asparagus racemosus Willd. & $\mathrm{KPK}^{*}$, Swat & " \\
\hline 12 & Asparagus densiflorus (Kunth) Jessop & Punjab, Lahore & Ornamental \\
\hline 13 & Asparagus setaceus (Kunth) Jessop & Punjab, Lahore & $"$ \\
\hline 14 & Asparagus plumosus Baker & $\mathrm{KPK}^{*}$, Swat & " \\
\hline
\end{tabular}

*KPK: Khyber PakhtunKhwa. 
Healthy fresh green leaves were collected, placed in a labeled sterile plastic cover, and stored in silica bags for further. DNA extraction method was employed to extract the genomic DNA from fresh green leaves of Asparagus as described by Doyle and Doyle (1987) with slight modifications. Around $20 \mathrm{mg}$ of the leaf material was well homogenized in $400 \mu \mathrm{L}$ of extraction buffer containing $100 \mathrm{mM}$ tris HCL, 25mM EDTA, $1.5 \mathrm{M} \mathrm{NaCl}, 2.5 \%$ CTAB, $1 \%$ PVP, $20 \mathrm{ml} \beta$ mercapto-ethanol with the help of sterilized pestle and mortar. The mixture was incubated at $65^{\circ} \mathrm{C}$ for $30 \mathrm{~min}$ in a water bath with intermittent shaking and vortexing. The mixture was then placed at room temperature for 10 minutes. Equal volume of Chloroform: isoamylalcohol $(24: 1, \mathrm{v} / \mathrm{v})$ was added to the tube and gently mixed. The mixture was centrifuged at $12,000 \mathrm{rpm}$ for 10 minutes at $24^{\circ} \mathrm{C}$. The aqueous phase was pipetted out in another centrifuge tube. Then equal volume of icecold isopropanol was added with addition of $5 \mathrm{M} \mathrm{NaCl}$. The DNA pellet was washed with wash buffer (Tris $\mathrm{HCl} 5 \mathrm{mM}, \mathrm{Nacl} 25 \mathrm{mM}$ and Etnanol 25\%) and then with $70 \%$ ethanol, air dried and finally resuspended in TE buffer ( $\mathrm{pH} 8$ ). DNA quality was visually evaluated on $0.8 \%$ of agarose gel electrophoresis and stored at $-20{ }^{\circ} \mathrm{C}$ for PCR amplification.

SSR markers especially developed for Asparagus genome (Idrees et al. 2019, Table S2) were amplified for different Asparagus species in a $25 \mu \mathrm{L}$ volume reaction mixture, containing $2.5 \mu \mathrm{L}$ of $10 \mathrm{X}$ EasyTaq buffer with $\mathrm{MgCl}_{2}, 10 \mathrm{mM}$ of $0.5 \mu \mathrm{L}$ of dNTP Mix, $1 \mu \mathrm{L}$ of each forward and reverse primer $(10 \mathrm{mmol} / \mathrm{L}), 1 \mathrm{U} / \mu \mathrm{L}$ of EasyTaq DNA polymerase and $2 \mu \mathrm{l}$ of $50 \mathrm{ng}$ of template DNA. PCR amplification reactions were performed in a 96 well thermal cycler (Applied Biosystem Inc. USA) using touchdown PCR protocol consisting of an initial step of denaturation at $95^{\circ} \mathrm{C}$ for 5 minutes. This was continued for 35 cycles of denaturation at $94{ }^{\circ} \mathrm{C}$ for 1 minute, primer annealing at 50 to $60{ }^{\circ} \mathrm{C}$ for 1.5 minutes, extension at $72{ }^{\circ} \mathrm{C}$ for 7 minutes and final extension at $72{ }^{\circ} \mathrm{C}$ for 7 minutes, with a hold temperature of $4^{0} \mathrm{C}$. PCR products were electrophoretically resolved on $2 \%$ agarose gels in $1 \mathrm{X}$ TBE buffer at $125 \mathrm{~V}$ for $90 \mathrm{~min}$. Gels were stained with ethidium bromide and photographed under UV transilluminator. The sizes of the amplified products were determined by comparing with a $1 \mathrm{~Kb}$ DNA ladder.

Table S2. Lists of 9 SSR markers and its forward and reverse sequences.

\begin{tabular}{llll}
\hline No. & Primers & Sequences (Forward) & Sequences (Reverse) \\
\hline 1 & psbD-trnL & CGTCCAATGCCCTTTACAAT & AATTTAGGGGCAGGGAAAAA \\
2 & PetB & AAGAGGCCTGTAACGAGCAA & CACAAATACTGATTTCACCGGATA \\
3 & ZHD1 & GGAAGAGGGTGCGTGTTTA & AAACGAACCAAAGTGCCATC \\
4 & AG7 & TTTTGCTCCGATCATTTTCA & CCTCTTCGTCTTCATCAGCC \\
5 & ITS1\&2 & CCGTGAACCATCGAGTCTTT & CAGCGTCTTTTGTCTGTCCA \\
6 & TC7 & CGCCCCGAATCAACTAATAA & TACTGCGGAGGTATGTGGGT \\
7 & rps16-trnK & TTCCTTGAAAAAGGTGCTCAA & GGTGGATTCCACAACAAGA \\
8 & AoAS1 & CTCATGCCCACTCCGATATT & TCAGCCTCCACGAACTCTCT \\
9 & trnQ-rps16 & ATGATTCACCATCCCGAAAA & TGAATAGTCATTGGATCAACGGTA \\
\hline
\end{tabular}

Analysis of electrophoresis patterns were scored for the presence and absence of bands. Numerical Taxonomy System (NT-SYS), version 2.11 from applied biostatistics Inc. (2002), was used to analyze the result obtained after bands scoring. Nei and Li genetic similarity coefficient was used to estimate the genetic similarity and genetic distances (Nei and Li 1979). Dendrogram for SSR fragments were generated using an Un-Weighted Pair Group Method Arithmetic Averages (UPGMA). 


\section{Results and Discussion}

DNA profiling of Asparagus species using nine genic SSR markers were performed which showed consistent reproducibility in their amplification (Table 1). These SSRs markers were found to reveal the allele polymorphism ranging from 1.0 to 2.0 for different Asparagus species. Majority of SSRs markers including psbD-trnL, petB, ZHD1, AG7, rps16-trnK and trnQ-rps16 have showed single allele for all Asparagus species, except TC7 and AoAS1, which have not showed any allele across all Asparagus species. Similarly, ITS1 and ITS2 have shown 2 alleles for all Asparagus species, except Asparagus densiflorus (Kunth) Jessop, in which only one allele was appeared (Table 1). Ginwal et al. (2011) has evaluated the cross-species amplification of microsatellite loci for different accessions of Asparagus racemosus. They have screened $18 \mathrm{cpSSR}$ markers for amplification, of which 5 cpSSR markers around $27.77 \%$ (AC03; AC-05; AC-09; AC-13 and AC-17) have revealed good cross-species amplification across 20 different individuals of A. racemosus. In the present study, Polymorphic Information Content, allele size range, and allele frequency for the SSRs alleles of Asparagus officinalis, cultivars and allied Asparagus species were also noticed. Size range (bp) for SSR alleles was found to range from $183 \mathrm{bp}$ (petB) to $1000 \mathrm{bp}$ (ITS1 and ITS2). Allele frequency was ranged from 0.1 (ZHD1-210) to 1.0 (psbDtrnL, petB and AG7). Polymorphism Information content (PIC) was highest for TC7 (0.9), while it was lowest (0.0) for psbD-trnL, petB and AG7 respectively. Most of the SSRs markers are monomorphic except ZHD1, TC7 and ITS1 and ITS2 (Table 2). Lal et al. (2010) have assessed the genetic diversity among five economically important Asparagus species using RAPDs markers. They noticed that the RAPD primers have yielded the amplification of 273 bands, among which 258 were polymorphic $(94.50 \%)$ while only 15 were monomorphic $(5.50 \%)$. The have noticed the high level of genetic diversity and low level of genetic similarity among five economically important Asparagus species. They revealed that high level of polymorphism could reflect the out-crossing nature of Asparagus species. These investigations provide an important baseline data for conservation and inter breeding programs. Similarly, Sica et al. (2005), have evaluated the ISSRs for the estimation of study genetic diversity in A. acutifolius italian populations. They have utilized twenty-three primers, which produced a total of 228 polymorphic fragments. Their diversity indices including FST (0.4561) and Theta B (0.4776) values have indicated a wide genetic variation among the A. acutifolius genotypes. UPGMA tree have grouped all these genotypes according to their geographical origin, revealing the level of genetic structure and distinct nature.

In the present study, the genetic similarity coefficients were also estimated that ranged from 0.42 to 1.0, revealing a high level of genetic variations for Asparagus officinalis, cultivars, and allied Asparagus species. This finding is in close agreement with the findings of Caruso et al. (2007). They have reported the methodology for generating Simple sequence repeat (SSR) markers from expressed sequence tag (EST) sequences. They have also applied these EST-SSRs for the level of estimation of genetic diversity among thirty-five Asparagus cultivars. Eight ESTSSR loci were found to be efficient for differentiating all the analyzed cultivars. Moreover, UPGMA (unweighted pair group method with arithmetic mean) and neighbor-joining trees, as well as principal components analysis have separated all these cultivars into clusters corresponding to their geographical origins. Similarly, Singh et al. (2013) have performed the molecular diversity analysis of 28 genotypes of 4 species of the genus Asparagus, namely: Asparagus racemosus, Asparagus falcatus, Asparagus officinalis and Asparagus plumosus using random amplified polymorphic DNA (RAPD). Around 25 RAPD primers have yielded a total of 296 RAPD fragments, of which 287 bands (96.95\%) were found to be polymorphic in the four species. Average polymorphic information content (PIC) value was 0.23 . Fourteen speciesspecific bands were found for A. racemosus species. These RAPDs markers have yielded high 


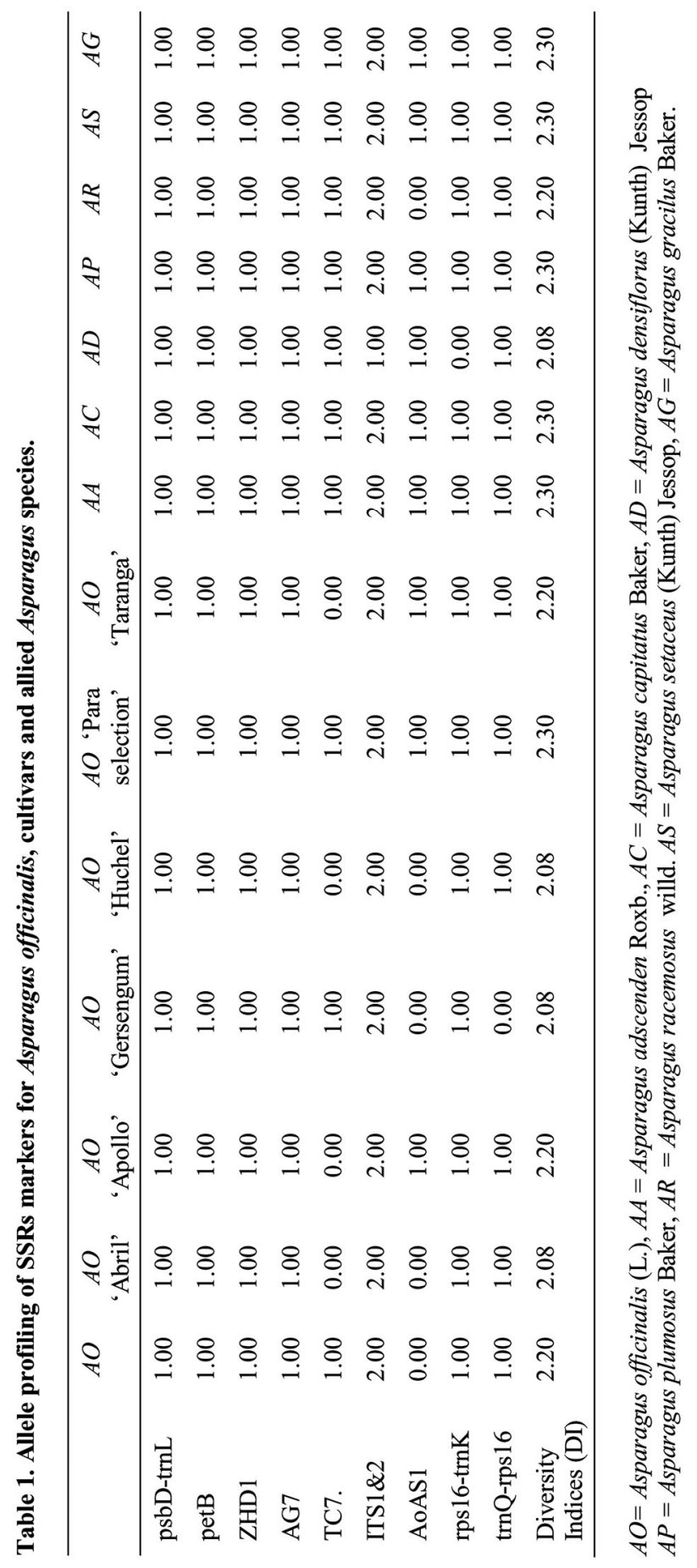


level of genetic variations for these Asparagus species. Genetic diversity among Asparagus species was also studied by other investigators including Lal et al. (2011), who had identified the similarity index ranging from 0.22 to 0.48 with a mean similarity of 0.36 indicating reasonable variability as obtained by RAPD markers. They have detected the high level of genetic diversity and low level of genetic similarity among five economically important Asparagus species. The polymorphism observed in present study, using SSR markers for Asparagus species and its cultivars were effective to determine genetic variation at species level.

Table 2. Polymorphic characteristics, allele size range and allele frequency for alleles of SSRs markers revealed for Asparagus officinalis, cultivars, and allied Asparagus species.

\begin{tabular}{lcccccc}
\hline & $\begin{array}{c}\text { Size range } \\
(\mathrm{bp})\end{array}$ & $\begin{array}{c}\text { Allele } \\
\text { Frequency }\end{array}$ & PIC $^{*}$ & Polymorphism & Monomorphism & $\begin{array}{c}\text { Diversity } \\
\text { Indices (DI) }\end{array}$ \\
\hline psbD-trnL. & 227 & 1.0 & 0.0 & 0.0 & 100.0 & 2.639 \\
petB & 183 & 1.0 & 0.0 & 0.0 & 100.0 & 2.639 \\
ZHD1 & 200 & 0.9 & 0.1 & 92.9 & 0.0 & 2.565 \\
& 210 & 0.1 & 1.0 & 7.1 & 0.0 & 0 \\
AG7 & 1000 & 1.0 & 0.0 & 0.0 & 100.0 & 2.639 \\
TC7 & 220 & 0.4 & 0.9 & 35.7 & 0.0 & 1.609 \\
& 230 & 0.4 & 0.9 & 35.7 & 0.0 & 1.609 \\
ITS1\&2 & 1000 & 0.9 & 0.1 & 92.9 & 0.0 & 2.565 \\
& 500 & 1.0 & 0.0 & 0.0 & 100.0 & 2.639 \\
AoAS1 & 220 & 0.6 & 0.6 & 0.0 & 100.0 & 2.197 \\
rps16-trnK & 200 & 0.9 & 0.1 & 0.0 & 100.0 & 2.565 \\
trnQ-rps16 & 197 & 0.9 & 0.1 & 0.0 & 100.0 & 2.565 \\
\hline
\end{tabular}

*Polymorphism Information content (PIC)

Cluster analysis using Nei and Li's coefficients has clustered Asparagus officinalis (L.), cultivars and allied Asparagus species into 4 groups (I, II, III \& IV) as shown in Fig. 1. Group 1 was further clustered into 2 subgroups including subgroup 'a', which was comprised of Asparagus officinalis (L.) that formed a clade with Asparagus officinalis (L.) 'Abril' and Asparagus officinalis (L.) 'Huchel'. Subgroup 'b' was further clustered into two clusters including cluster ' $i$ ' that was comprised of Asparagus officinalis (L.) 'Apollo', Asparagus officinalis (L.) 'Taranga', Asparagus officinalis (L.) 'Para selection', Asparagus adscenden Roxb., and Asparagus capitatus Baker. Similarly, Subgroup 'b' was clustered into another cluster "ii" that was comprised of Asparagus plumosus Baker, Asparagus setaceus (Kunth) Jessop, and Asparagus gracilus Salisb. Similarly, Asparagus officinalis (L.) 'Gersengum' was clustered into group II, Asparagus densiflorus (Kunth) Jessop was clustered to group III while Asparagus racemosus willd. was clustered into group IV. It was revealed that Asparagus species of group II, III and IV were variable from Asparagus officinalis (L.) species of group I, suggesting that these were the most primitive species of genus Asparagus.

The results of the present study are in agreement with the results of Altıntaş et al. (2019), which have revealed similar pattern of genetic diversity for Asparagus species. They have evaluated Asparagus species using rDNA ITS, cpDNA trnL Intron sequences. Phylogenetic analysis based on ITS data have revealed Asparagus species into two clades: the first clade consisted of Asparagus persicus and Asparagus officinalis, and clade II consisted of Asparagus palaestinus. Similarly, Castro et al. (2012) have also assessed the genetic diversity and phylogenetic relationships of Asparagus species and allied Asparagus officinalis. Phylogenetic 


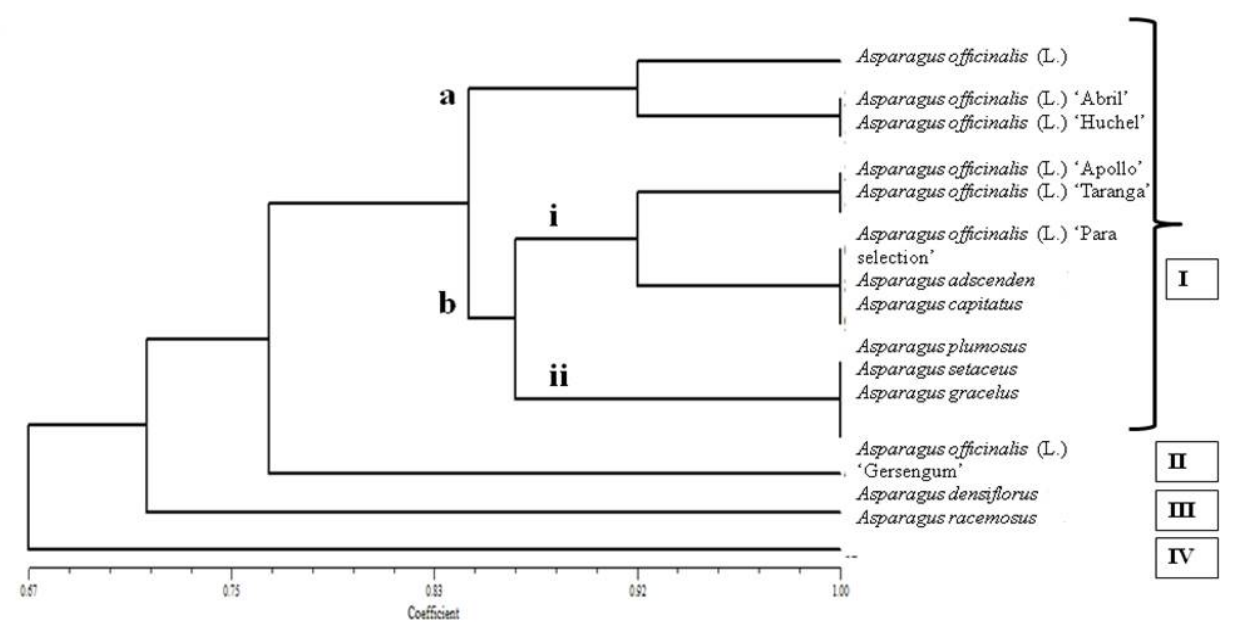

Fig. 1. Cluster analysis of Asparagus officinalis, cultivars and allied Asparagus species using Nei and Li's coefficients.

analysis using ITS data have clustered Asparagus species into two major clades including clade I, which was consisted of $A$. acutifolius while clade II (referred to in this study as the 'officinalis group') was comprised of sequences derived from species closely related to A. officinalis. It was further revealed that group of species classified in the 'officinalis group' are the primary gene pool, indicating that these species can be used to increase the genetic diversity of the cultivated $A$. officinalis genotypes. The present study has endorsed the origin status of Asparagus officinalis and their allied species. A. officinalis cultivars and other allied Asparagus species are clustered in separate clades, and it was revealed that they have monophyletic origin. It was established that these SSRs markers could be informative markers for the differentiation of Asparagus officinalis cultivars, and allied Asparagus species, and these markers can be used for association mapping and for phylogenetic studies.

\section{Acknowledgements}

This research was financed by the Scientific Research Project of Neijiang Normal University (2020WJ02). The authors are grateful to Dr. Maryam Shinwari (Quaid-E-Azam University) and Mr. Maazullah (Agriculture Research Institute) for the facilities provided during sampling of Asparagus species. The Research work was carried out in the Department of Biotechnology and Genetic Engineering, KUST, Kohat, Pakistan.

\section{References}

Altıntaş S, Pakyürek M, Şensoy S, Erez ME and İnal B 2019. Genetic Diversity among Some Asparagus Species using rDNA ITS, cpDNA trnL Intron Sequence and Screening for Antioxidant Activity. Pol. J. Env. Stud. 28(4): 2049-2055.

Caruso M, Federici CT and Roose ML 2008. EST-SSR markers for Asparagus genetic diversity evaluation and cultivar identification. Mol. Breed. 21(2): 195-204.

Castro P, Gil J, Cabrera A and Moreno R 2013. Assessment of genetic diversity and phylogenetic relationships in Asparagus species related to Asparagus officinalis. Genet. Resour. Crop Ev. 60: 12751288.

Doyle JJ and Doyle JL 1987. A rapid DNA isolation procedure for small quantities of fresh leaf tissue. Focus 19: $11-15$. 
Engles JMM, Rao VR, Brown AHD and Jackson MT 2002. Managing plant genetic diversity CABI Publishing UK pp: 487.

Fuentes-Alventosa J, Jaramillo-Carmona S, Rodri'guez-Gutie'rrez G, Rodri'guez-Arcos R, Ferna'ndez Bolaños J, and Guille'n-Bejarano R 2009. Effect of the extraction method on phytochemical composition and antioxidant activity of high dietary fibre powders obtained from asparagus by-products. Food Chem. 116: 484-490.

Ginwal HS, Mittal N, Maurya SS, Barthwal S and Bhatt P 2011. Genomic DNA isolation and identification of Chloroplast microsatellite markers in Asparagus racemosus Wild. Through cross amplification. Ind. J. Biotechnol. 10: 33-38.

Hafizur RM, Kabir N and Chishti S 2012. Asparagus officinalis extract controls blood glucose by improving insulin secretion and $\beta$-cell function in streptozotocin-induced type 2 diabetic rats. Brit. J. Nut. 108: 1586-1595.

Idrees M, Irshad M, Pathak ML, Tariq A and Rehan N 2019. Genetic diversity among Asparagus species and cultivars using SSR markers. J. Biodivers. Conserv. Bioresour. Manag. 4(2): 21-32.

Kalpana J, Warude PC and Bhushan P 2004. Molecular markers in herbal drug technology. Curr Sci. 87: 159-165.

Kanno A and Yokoyama J 2011. Asparagus. In: Kole C, editor. Wild Crop Relatives: Genomic and Breeding Resources: Vegetables Berlin, Germany, Springer pp: 23-42.

Koppolu R, Upadhyaya HD, Dwivedi SL, Hoisington DA and Varshney RK 2010. Genetic relationships among seven sections of genus Arachis studied by using SSR markers. BMC Plant Biol. 10(1):15.

Kubota S, Konno I and Kanno A 2012. Molecular phylogeny of the genus Asparagus (Asparagaceae) explains interspecific crossability between the garden Asparagus (A. officinalis) and other Asparagus species. Theor. Appl. Genet. 124: 345-354.

Kumar M, Kumar Naik PS and Chhocar V 2015. Genetic variations in Asparagus racemosus, an endangered medicinal herb endemic to India using RADP markers. Br. Biotechnol. J. 10: 1-11.

Lal S, Kinnari NM, Parth BV, Smit DS and Riddhi AT 2011. Genetic diversity among Five Economically important species of Asparagus collected from central Gujrat (India) Utilizing RAPD Markers (Random Amplification of Polymorphic DNA). Int. J. Adv. Biotechnol. Res. 2(4): 414-421.

Lee EJ, Yoo KS and Patil BS 2010. Development of a Rapid HPLC-UV Method for Simultaneous Quantification of Protodioscin and Rutin in White and Green Asparagus Spears. J. Food Sci. 75: C703-9.

Maeda T, Kakuta H, Sonoda T, Motoki S, Ueno R, Suzuki T et al. 2005. Antioxidation capacities of extracts from green, purple, and white aAsparagus spears related to polyphenol concentration. Hort. Sci. 40: 1221-1224.

Nei M and Li W 1979. Mathematical model for studying genetic variation in terms of restriction endonucleasis. Proc. Natl. Acad. Sci. 76: 5269-527.

Norup MF, Petersen G, Burrows S, Bouchenak-Khelladi Y, LeebensMack J, Pires JC, Peter Linder H and Seberg O 2015. Evolution of Asparagus L. (Asparagaceae): Out-of-South-Africa and multiple origins of sexual dimorphism. Mol. Phyl. Evol. 92: 25-44.

Ray S, Madhumita JM and Sandip M 2010. Phylogenetic relationship among six economically important species of Asparagus utilizing RAPD, ISSR and isozyme polymorphism. Biores. Bull. 3: 153-60.

Sica M, Gamba G, Montieri S, Gaudio L. and Aceto S 2005. ISSR markers show differentiation among Italian populations of Asparagus acutifolius L. BMC Genet. 6:1-7.

Singh A, Rai VP, Singh M, Singh AK and Sinha B 2013. Molecular diversity analysis of Asparagus racemosus and its adulterants using random amplified polymorphic DNA (RAPD). J. Med. Pl. Res. 7(16):1050-1056. 